\title{
Boeing 737-800 and MAX 8 Critical Factor Simulation
}

\author{
J.K.Rahul Jayawardana ${ }^{\mathrm{a}}$ \\ a jayawardanarahul@gmial.com \\ ${ }^{a}$ Sri Lanka Telecom Training Center, Welisara ,Colombo \\ ${ }^{b}$ Institute of Electrical and Electronics Engineering ,IEEE(std)
}

\begin{abstract}
Boeing 737 is one of the most widely used aircraft in hundreds of airlines around the world. The Boeing Company introduced the new modified series of the 737 family Boeing 737 MAX series in 2015 and the Boeing 737 MAX 8 entered the commercial service in 2016. The MAX 8 is a state of the art aircraft that is more computerized and modified using the application of improved aerodynamics and safety systems. But since the crashes of Lion Air JT610 and Ethiopian Airlines ET302 which were operated with Boeing 737 MAX 8 aircraft, the global MAX 8 fleet became grounded officially due to safety reasons. The investigations said the activation of the MCAS (A safety system) played major roles in both crashes. In this research, the other factors except for the MCAS which are, take-off angles, stall angle and stall times, and V1 \&V2 speeds of the MAX8 were simulated and compared with its predecessor Boeing 737-800 using the Microsoft Flight Simulator X.
\end{abstract}

Published by IJRP.ORG. Selection and/or peer-review under responsibility of International Journal of Research Publications (IJRP.ORG)

Keywords: Type your keywords here, separated by semicolons ;

\section{Introduction}

Boeing is one of the leading aircraft and aerospace crafts manufacturers that designed most of the glorious jets in civil aviation for more than half a century. Boeing 737, Boring 747 and Boeing 777 are some of the most widely used passenger jets in the civil aviation industry today. The Boeing 737 family is still a giant in the industry used by more than $90 \%$ of the airlines across the world. The most popular and widely used Boeing 737-800 is the best design so far by the Boeing, because of the improved stability and the safety systems. Boeing 737 MAX 8 was introduced under the Boeing 737 MAX series in 2016 to improve and increases the value of the Boeing 737 aircraft by taking it to the next generation civil aviation operations more safely and efficiently. The aircraft was a success until two of the Boeing 737 MAX 8 aircraft faced two fatal crashes leaving no survivors. The Lion Air flight JT610 and Ethiopian Airlines flight ET302 operated by two MAX 8 aircraft crashed minutes after the take-offs. There both crashes and the clues showed similar characteristics and behaviours in their investigations. The new stall avoiding system added on board the MAX 8 called the 
Manoeuvring Characteristics Augmentation System or the MCAS has given a major contribution for both crashes according to the investigation reports by the FAA and NTSB. And as a result the entire Boeing 737 MAX 8 fleet was officially grounded in 2019 since the aircraft is considered to be less reliable and unpredictable.

In this research, the Boeing 737 MAX 8 is compared and tested with the Boeing 737-800 to observe and determine the critical factors (except MCAS) of both aircraft. For the simulation purpose, Microsoft Flight Simulator X was used.

\begin{tabular}{|l|}
\hline Nomenclature \\
\hline MCAS - Manuevering Characteristics Augmentation System \\
$\mathrm{V} 1$ - The speed where the aircraft exceeds the point of stopping on the runaway in case of a take-off aboard. \\
$\mathrm{V} 2$ - The minimum speed that the aircraft will be able to climb in case of a one engine failure. \\
$\mathrm{Vr}$ - The speed or the point where the pilot stats to pitch the nose up to lift off from the runaway. \\
AOA - Angle of Attack
\end{tabular}

\section{Materials and Methods}

To conduct simulation and to test the behaviors of critical factors in Boeing 737-800 and MAX 8, Microsoft Flight Simulator X was used. For the Data analysis and the representative purpose Microsoft Office package, 2016 was used mainly MS word for documentation and the MS Excel for data analysis. The Main and critical factor of the aircraft were identified as,

1. Take off angles (Pitch Angles)

2. V1 and V2 Speeds Comparison

3. Stall angle and Stall time comparison

4. Weight conditions comparisons

5. Evaluating the stability and other factors of Boeing 737-800 and MAX 8.

For determining the takeoff angles and V1, V2 speeds the simulations were conducted on the Microsoft flight simulator X. Stall angles and stall times were also determined using the simulations. Other critical factors were evaluated based on the secondary data and all the simulation setups and their initial conditions were given according to the international civil aviation standards regarding each aircraft model.

\section{Simulations and Results}

There are 8 flap settings on the 737-800, with each having a different angle. These different angles allow the pilots to control how much lift the wings generate. Here are the angles below.

Flaps $1-8^{\circ}$

Flaps $2-11^{\circ}$

Flaps $5-14^{\circ}$

Flaps $10-19^{\circ}$

Flaps $15-22^{\circ}$

Flaps $25-26^{\circ}$

Flaps 30 - $35^{\circ}$

Flaps $40-46^{\circ}$

8 , various weight conditions. 


\section{Flaps and Airspeeds}

You use different amounts of flaps in different airspeeds. If you want more lift, you need more flaps and vice versa. Here are the airspeeds in which each set of flaps should be used to prevent damage, and maximize lift.

Flaps Up - 210KTS

Flaps 1 - 190KTS

Flaps 5 - 170KTS

Flaps 10 - 160KTS

Flaps 30 - 130KTS

Flaps 40 - 120KTS

Flaps 2, 15, and 25 are not normally used during flight hence why they are not on this list. Flaps 5, 15, and 25 are primarily used for takeoffs. In adverse weather conditions, taxi with the wing flaps up and then set takeoff flaps during your Before Takeoff checklist procedure. When extending or retracting the flaps, use the next appropriate flap setting depending on whether you're slowing down or speeding up.

Source - https://community.infiniteflight.com/t/using-the-737-800-900-flaps/191982

\subsection{Testing the pitch angles and trim positions}

For this test both Boeing 737-800 and Boeing 737, Max 8 will use their take-off flaps position at Flaps 15. Flap position 15 is used because it is the middle value between flap position 5 and 25 , which are generally used in the takeoff.

The elevator trim is Elevator 1.8 Upward pitch. Since both aircraft have balanced loads the elevator trim is only used to trim, not balancing.

The weather selected is the minimum wind speed and almost zero turbulences. Therefor any other trimming surfaces will not be used.

\subsubsection{Boeing 737-800 takes off-angle data}

Flaps $15 \quad$ Elevator 1.8 upward Fuel weight $($ At $\max )-20.762 \mathrm{Ton}$ Airline- Lion Air Boeing 737-800

Flight Number - Test $1 \quad$ Time - 9.30 AM Whether - Clear skies

Location - San Francisco International Airport, California, USA

Table 3.1 - Boeing 737-800 Pitch angle behavior test inputs

\begin{tabular}{|l|l|l|l|l|l|l|}
\hline 1. & 2. Weight(kg) & 3. Trim & 4. Flaps & 5. V1(knots) & 6. Vr(knots) \\
10. & 11. & 7. Angle \\
8. Payload & 9. Fuel & 1. & 14. \\
\hline 15.0 & 16.20762 .736 & $17 .+1.8$ & 18.15 & 19.180 & 20.190 & $21.15+$ \\
\hline 22.2517 .438 & 23.20762 .736 & $24 .+1.8$ & 25.15 & 26.129 & 27.135 & $28.15+$ \\
& & & & & & \\
\hline 29.4014 .292 & 30.20762 .736 & $31 .+1.8$ & 32.15 & 33.130 & 34.139 & $35.11+$ \\
& & & & & & \\
\hline 36.5375 .069 & 37.20762 .736 & $38 .+1.8$ & 39.15 & 40.130 & 41.138 & $42.16+$ \\
& & & & & & \\
\hline
\end{tabular}




\begin{tabular}{|c|c|c|c|c|c|c|}
\hline 43.5828 .662 & 44.20762 .736 & $45 .+1.8$ & 46.15 & 47.132 & 48.138 & $49.11+$ \\
\hline 50.7643 .0314 & \begin{tabular}{|l|}
51.20762 .736 \\
\end{tabular} & $52 .+1.8$ & 53.15 & 54.145 & 55.156 & $56.13+$ \\
\hline 57.8550 .216 & \begin{tabular}{|l|}
58.20762 .736 \\
\end{tabular} & $59 .+1.8$ & 60.15 & 61.135 & 62.145 & $63.10+$ \\
\hline 64. 10364.586 & \begin{tabular}{|l|}
65.20762 .736 \\
\end{tabular} & $66 .+1.8$ & 67.15 & 68.145 & 69.154 & $70.12+$ \\
\hline
\end{tabular}

With the constant maximum fuel load, Boeing 737-800 shows the following variation between the payload weight and the pitch angle.

Graph 3.1.1 - Boeing 737-800 Take off-pitch angle data

\section{Boeing 737-800 Take off Pitch angle data}

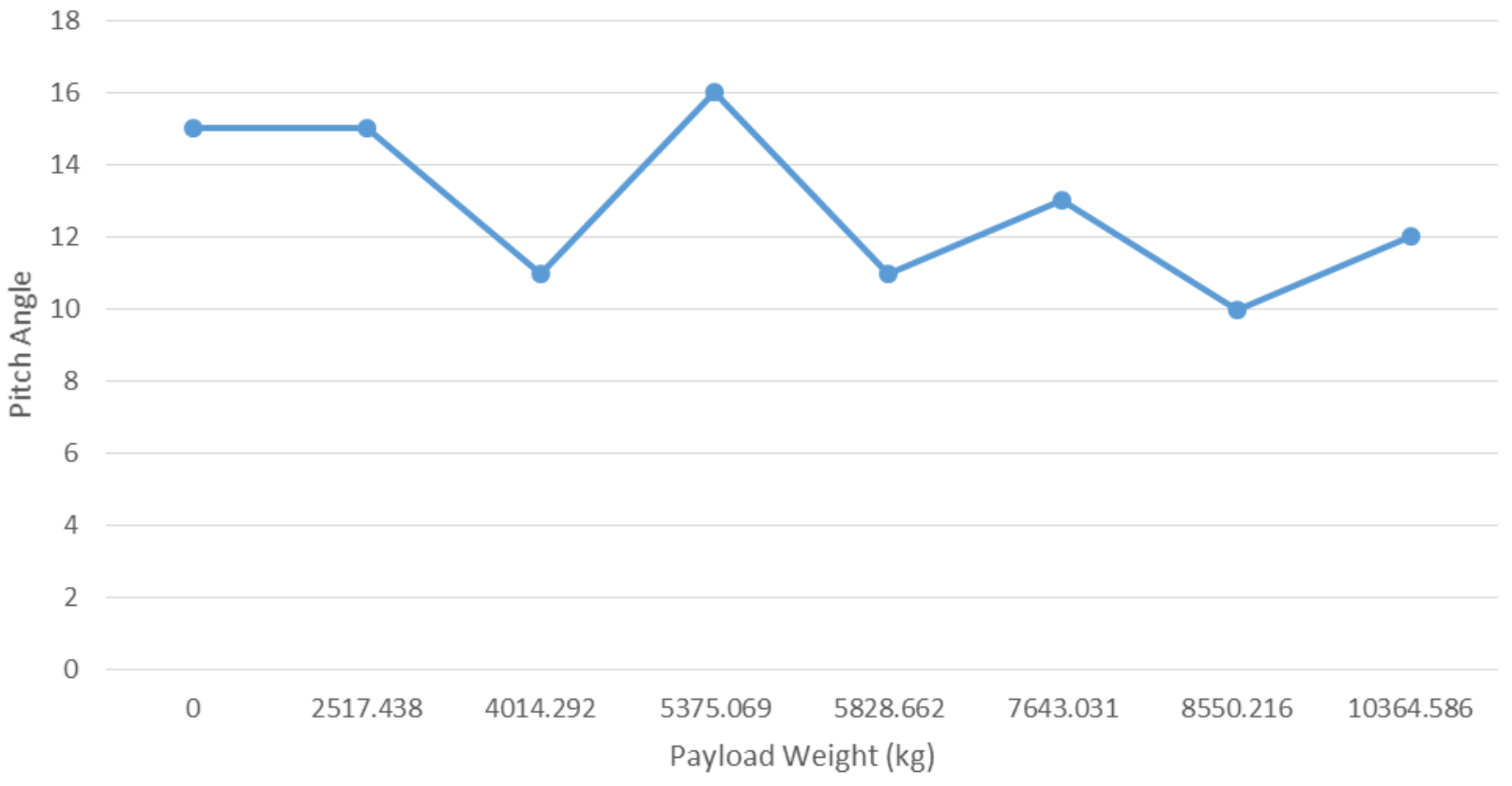


Conclusion 3.1.1 - The maximum pitch angle is reached at the payload of $5375.069 \mathrm{~kg} \mathrm{~s}$.

The full payload of the aircraft is $10364.586 \mathrm{~kg}$ therefore according to the above data the maximum takeoff pitch angle is reached at $51.8599 \%$ of its payload. (With max fuel load).It is approximately $52 \%$.

\subsubsection{Boeing 737 Max 8 take-off angle data}

Flaps $15 \quad$ Elevator 1.8 upward Fuel weight (At max) - 20.762Ton

Airline- Lion

Air Boeing 737 Max 8

Flight Number - Test $21 \quad$ Time - 9.30 AM Whether-Clear skies

Location - San Francisco International Airport, California, USA

Max Fuel - $20732.8 \mathrm{~kg} \quad$ Max payload - $17936.403 \mathrm{~kg}$

Table 3.2 - Boeing 737 Max 8 pitch angle behavior test inputs

\begin{tabular}{|c|c|c|c|c|c|c|}
\hline 71. & 72. Weight & 73. Trim & 74. Flaps & 75. V1(knots) & 76. $\operatorname{Vr}$ (knots) & 77. Angle \\
\hline 78. Payload & 79. Fuel & & 81. & & & \\
\hline 85.0 & 86.20732 .8 & $87 .+1.8$ & 88.15 & 89.120 & 90.145 & 91.8 \\
\hline 92.2517 .438 & 93. 20732.8 & $94 .+1.8$ & 95.15 & 96.118 & 97.145 & 98.8 \\
\hline 99. 4014.292 & 100.20732 .8 & $101 .+1.8$ & 102.15 & 103.120 & 104.148 & 105.8 \\
\hline 106.5375 .069 & 107. 20732.8 & $108 .+1.8$ & 109.15 & 110.125 & 111.150 & 112.8 \\
\hline 113.5828 .662 & 114. 20732.8 & $115 .+1.8$ & 116.15 & 117.130 & 118.150 & 119.8 \\
\hline 120.7643 .0314 & 121.20732 .8 & 122. +1.8 & 123.15 & 124. 135 & 125.152 & 126.8 \\
\hline 127.8550 .216 & 128. 20732.8 & $129 .+1.8$ & 130.15 & 131.135 & 132.150 & 133.8 \\
\hline 134. 10364.586 & 135. 20732.8 & 136. +1.8 & 137.15 & 138.145 & 139.160 & $140.5+$ \\
\hline 141.17936 .403 & 142.20732 .8 & $143 .+1.8$ & 144.15 & 145.145 & 146.155 & $147.5+$ \\
\hline
\end{tabular}


Graph 3.1.2 - Boeing 737 Max8 pitch angle behavior

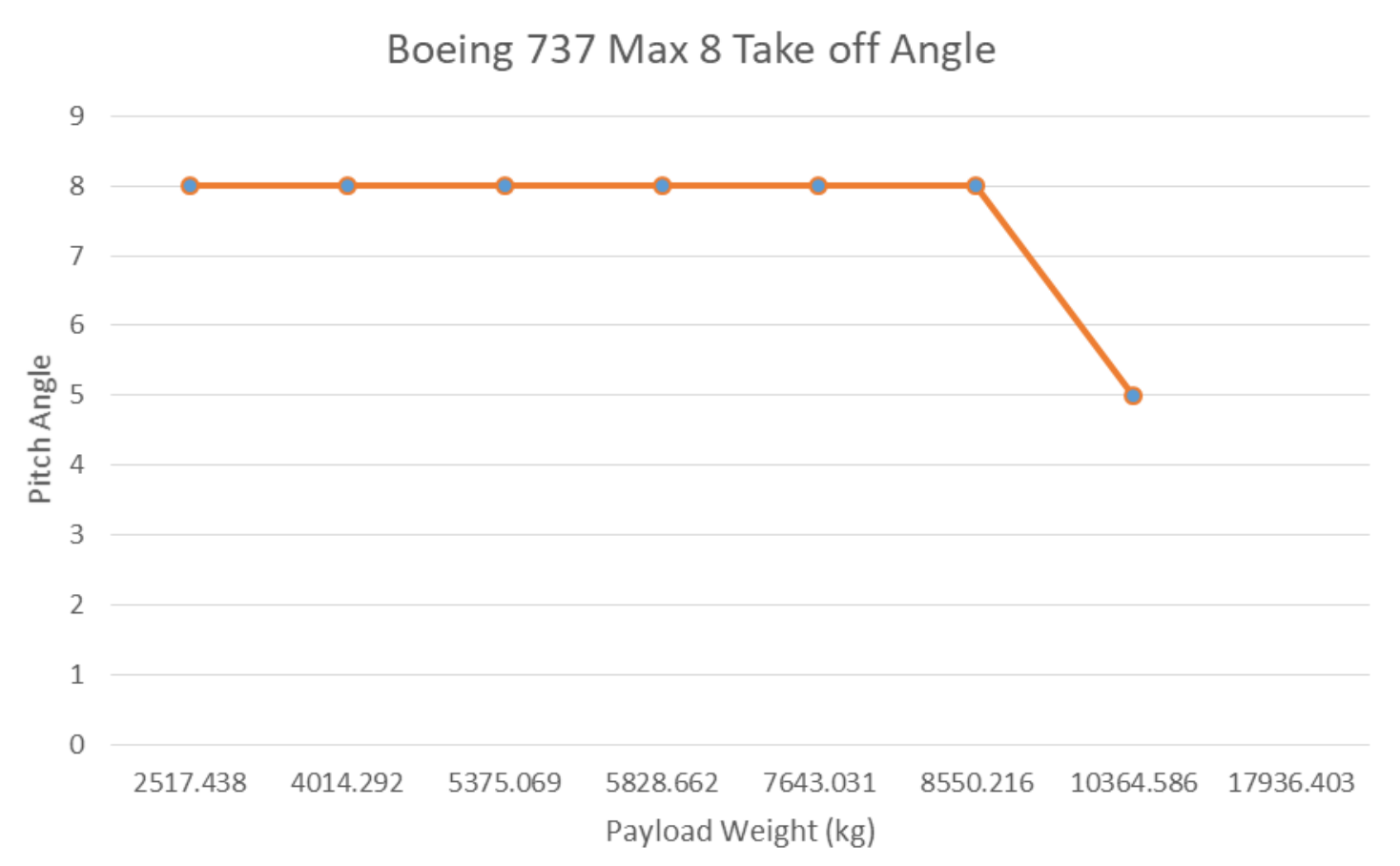

Graph 3.1.3 - Pitch angle behavior comparison (Boeing737-800 vs. Boeing 737Max8)

\section{Pitch Angle Behaviour Comparison}

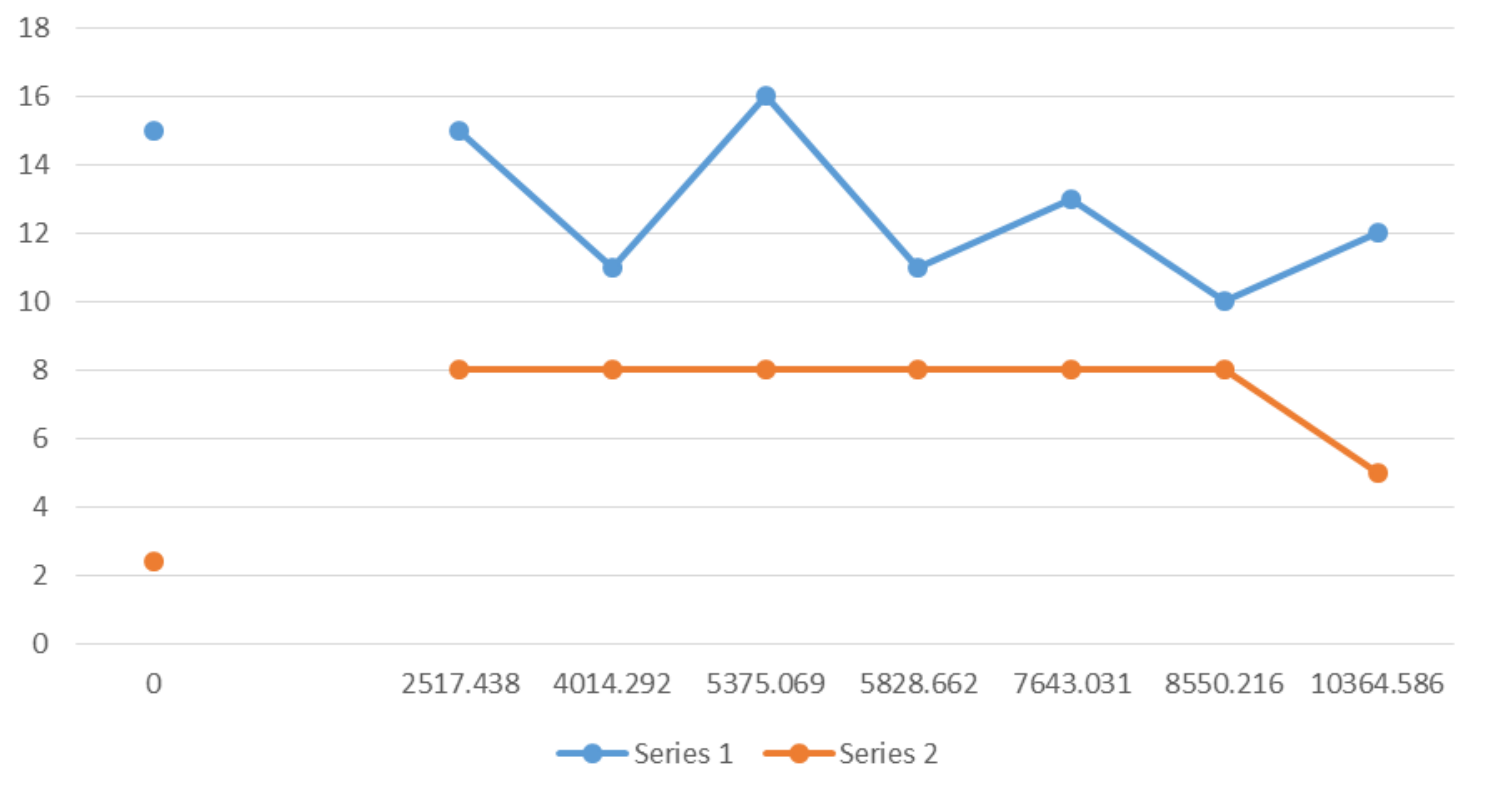


According to the above data the pitch angle of the Boeing 737, max 8 appears to be a constant 8 degrees without exceeding the margin of 10 degrees. This situation is extremely dangerous in a practical scenario and can lead to terrible disasters. Therefore the pitch angle of the Boeing 737 max 8, which will give the same pitch angle of the Boeing 737-800 under the same weight conditions should be determined.

\subsubsection{Trim Positions}

Test method 1 -To determine the elevator trim position of the being 737 Max 8, that will give the same pitch angle of the Boeing 737-800 at the same weight conditions following method is used.

I. Initial conditions were set to Flaps 15, Elevator trims 1.8 upward.

II. Took off normally with the same weather conditions and time from the same airport.

III. Shortly after the takeoff, the elevator trim was gradually increased until it gives the same corresponding take-off angle of the Boeing 737-800 and it was recorded.

Table 3.1.3 - Elevator trim position inputs

\begin{tabular}{|c|c|c|c|c|}
\hline 148. Weight $(\mathrm{kg})$ & \multicolumn{2}{|c|}{$\begin{array}{l}\text { 149. Boeing 737- } 150 . \\
800\end{array}$} & \multicolumn{2}{|c|}{ 151. Being 737Max 8152.} \\
\hline 153. & 154. Trim & 155. Angle & 156. Trim & 157. Angle \\
\hline 158.0 & 159.1 .8 & $160.15+$ & 161.3 .4 & $162.15+$ \\
\hline 163.2517 .438 & 164.1 .8 & $165.15+$ & 166.3 .7 & $167.15+$ \\
\hline 168. 4014.292 & 169.1 .8 & $170.11+$ & 171.3 .8 & $172.11+$ \\
\hline 173.5375 .069 & 174.1 .8 & $175.16+$ & 176.3 .6 & $177.16+$ \\
\hline 178.5828 .662 & 179.1 .8 & $180.11+$ & 181.3 .7 & $182.11+$ \\
\hline 183.7643 .0314 & 184.1 .8 & $185.13+$ & 186.3 .5 & $187.13+$ \\
\hline 188.8550 .216 & 189.1 .8 & 190. 10+ & 191.3 .6 & $192.10+$ \\
\hline 193. 10364.586 & 194.1 .8 & $195.12+$ & 196. 3.9 & $197.12+$ \\
\hline
\end{tabular}

According to the above test results, the average elevator trim positions for various weight conditions of both aircraft are as follows.

Boeing 737-800 - $\quad 1.8$ upward position

Boeing 737Max8- 3.6 upward position

Well, it reveals that the Boeing 737Max8 is demanding double the amount of the elevator pitch trim, then the Boeing 737-800 to provide the same climbing angle under the equal weight conditions.

\subsubsection{V1 and V2 Speeds}

The V1 speed and the Vr speed are giving approximately close values in the Boeing 737-800 and they are reducing when the payload is reducing. But in Max 8 the V1 speed is the only one reducing with the weight and the $\mathrm{Vr}$ speed is changing slightly.

Boeing 737-800 V1 and Vr 
Graph 3.1.4 - V1 and V2 speeds comparison of Boeing 737-800

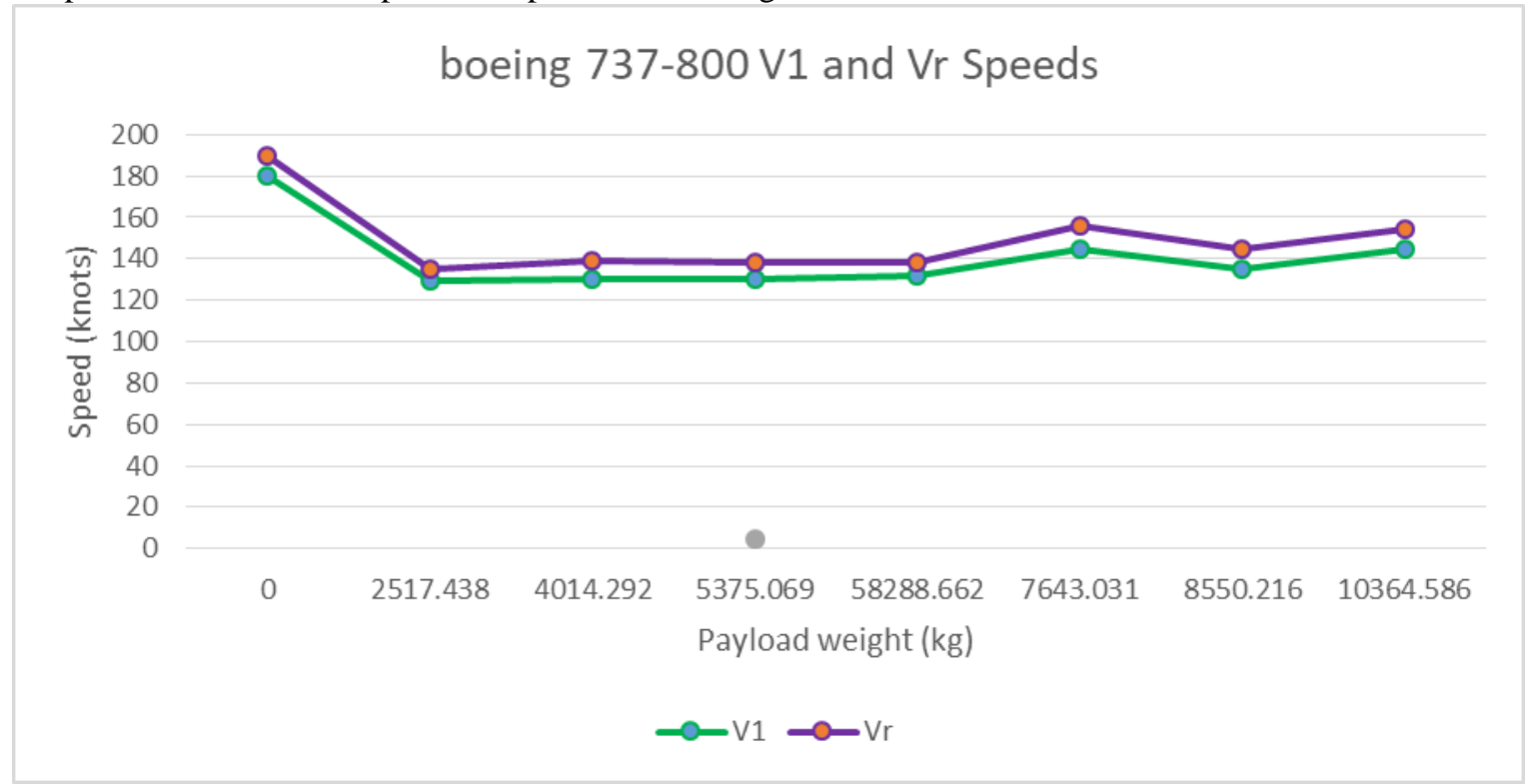

Boeing 737 Max $8 \mathrm{~V} 1$ and Vr speeds

Graph 3.1.5 - V1 and V2 speeds comparison of Boeing 737 Max 8

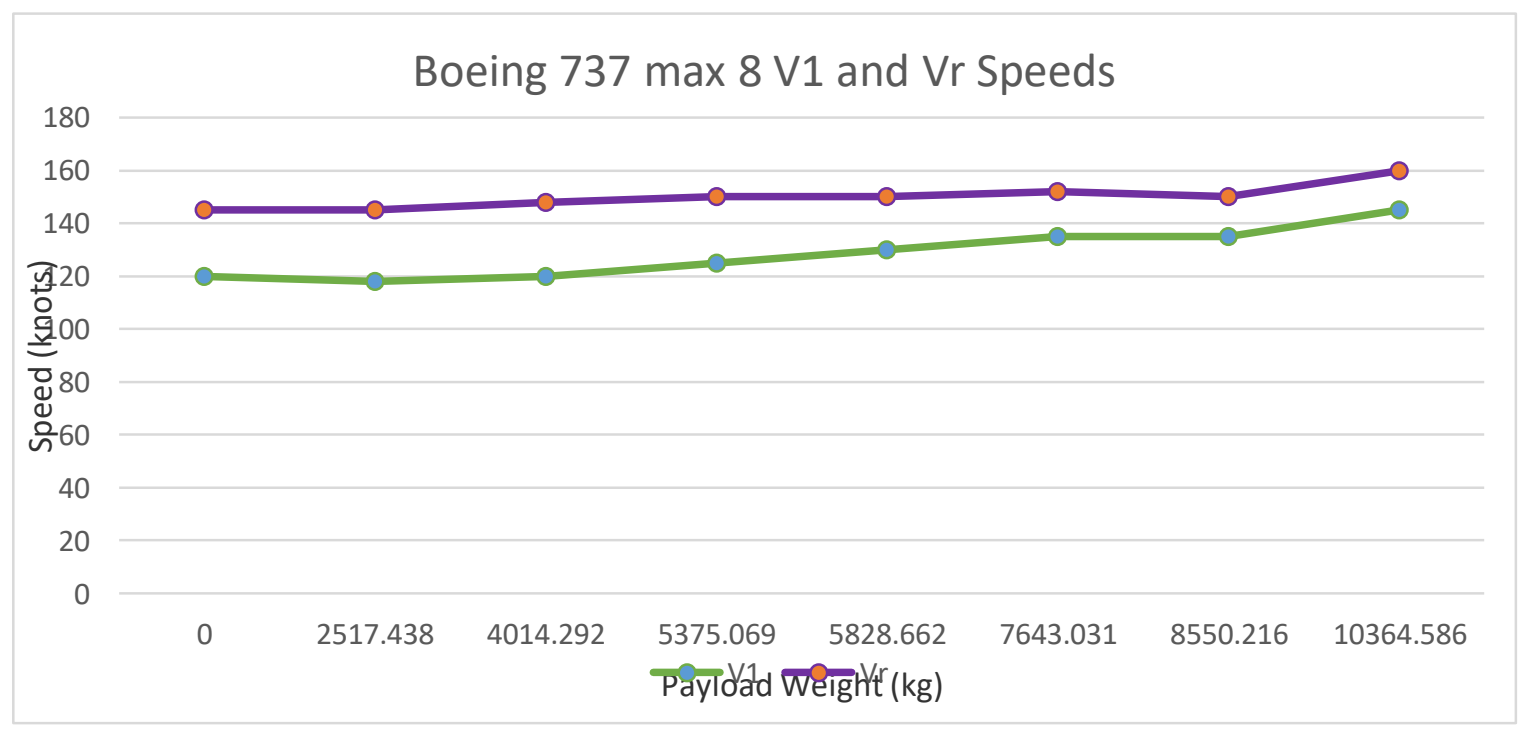

According to the above comparison Boeing 737, max 8 is having an increased difference between the V1 and V2 speeds at low weight conditions. 
Conclusions 3.1.2

01. Boeing 737 - 800 is giving smooth take-off angles under all weight conditions, with less trimming.

Boeing 737Max 8 gives the same take-off angles under the same equal weight conditions with double the trimming needed for Boeing 737-800.

02. Boeing $737-800$ is having close values in the V1 and Vr speeds, in various weights. And the difference between the two values is almost constant.

Boeing 737Max 8 is having close values in $\mathrm{V} 1$ and $\mathrm{Vr}$ speeds under heavy payloads and the difference between them tends to tend to be increased when the payload is reducing.

3.2. Stall margin and coffin corner Analysis of Boeing 737-800 and Boeing 737 max 8

The test was conducted at a virtual height of $10000 \mathrm{ft} \mathrm{s}$ above the mean sea level. And according to the standard commercial aviation rules, the airspeed corresponding to that height is 250 knots.

And to make the aircraft into the stall position the throttle was reduced to a fixed $40 \%$ position.

\subsubsection{Boeing 737-800 Stall margin analysis}

Table 3.2.1 - Boeing 737-800 stall simulation

\begin{tabular}{|l|l|l|l|}
\hline 198. Weight & $\begin{array}{l}\text { 199. Speed before stall } \\
200 . \text { (knots) }\end{array}$ & $\begin{array}{l}\text { 201. Time is taken } \\
\text { to Stall } \\
\text { 202. (seconds) }\end{array}$ & $\begin{array}{l}\text { 203. Angle } \\
\text { 204. (degrees) }\end{array}$ \\
\hline 205.0 & 206.250 & $\begin{array}{l}207.19 .69 \\
\text { 208. vertical turn around } \\
\text { reaches 70(110) }\end{array}$ \\
\hline 209.2517 .438 & 210.250 & $\begin{array}{l}\text { 212. vertical turn around } \\
\text { reaches } 85(95)\end{array}$ \\
\hline 213.4014 .292 & 214.250 & 215.23 .85 & 216.70 \\
\hline 217.5375 .069 & 218.250 & 223.07 & $\begin{array}{l}220 . \text { vertical turn around } \\
\text { reaches } 80(100)\end{array}$ \\
\hline 221.5828 .662 & 222.250 & 227.37 & 224.75 \\
\hline 229.8550 .216 & 226.250 & 231.35 .21 & 228.52 \\
\hline 233.10364 .586 & 230.250 & 235.20 .12 & 236.60 \\
\hline
\end{tabular}

Considering the above data the average time taken for a Boeing 737-800 to stall is 24.34 seconds. And the average stalling angle of the Boeing 737-800 is 82.125 degrees positive pitch. 
3.2.2. Boeing 737 Max 8 stall margin analysis.

Table 3.2.2 - Boeing 737 Max 8 stall simulation

\begin{tabular}{|l|l|l|l|}
\hline 237. Weight & $\begin{array}{l}\text { 238. Speed before Stall } \\
\text { 239. (knots) }\end{array}$ & $\begin{array}{l}\text { 240. Time is taken } \\
\text { for stall } \\
\text { 241. (seconds) }\end{array}$ & $\begin{array}{l}\text { 242. Angle } \\
\text { 243. (degrees) }\end{array}$ \\
\hline 244.0 & 245.250 & 246.30 .44 & 247.88 \\
\hline 248.2517 .438 & 249.250 & 250.35 .62 & 251.87 \\
\hline 252.4014 .292 & 253.250 & 254.27 .40 & $\begin{array}{l}255.90 \text { close to vertical } \\
\text { turn over(90) }\end{array}$ \\
\hline 256.5375 .069 & 257.250 & 258.24 .73 & 259. vertical turn over(90) \\
\hline 260.5828 .662 & 261.250 & 262.23 .79 & 263. vertical turn over(90) \\
\hline 264.7643 .0314 & 265.250 & 266.24 .56 & 267.85 \\
\hline 268.8550 .216 & 269.250 & 270.27 .45 & 271.75 \\
\hline 272.10364 .586 & 273.250 & 274.20 .98 & 275.70 \\
\hline
\end{tabular}

According to the above data, it takes an average time of 26.871 seconds for a Boeing 737 Max 8 to become the stall position. And the average stall angle for Boeing 737 Max 8 is 84.375 degrees positive pitch.

Conclusion 3.2.1

When analyzing the stall data of the 737-800 the aircraft is showing an average stall angle of 82.125 degrees and 24.34seconds of time for a stall at the speed of 250 in 1000fts.Boeing 737 Max 8 shows an average stall angle of 84.375 degrees with 26.871 seconds to reach the stall point at 250 knots in $1000 \mathrm{fts}$. 
Graph 3.2.1- Boeing 737-800 and Boeing 737 max 8 stall time comparison

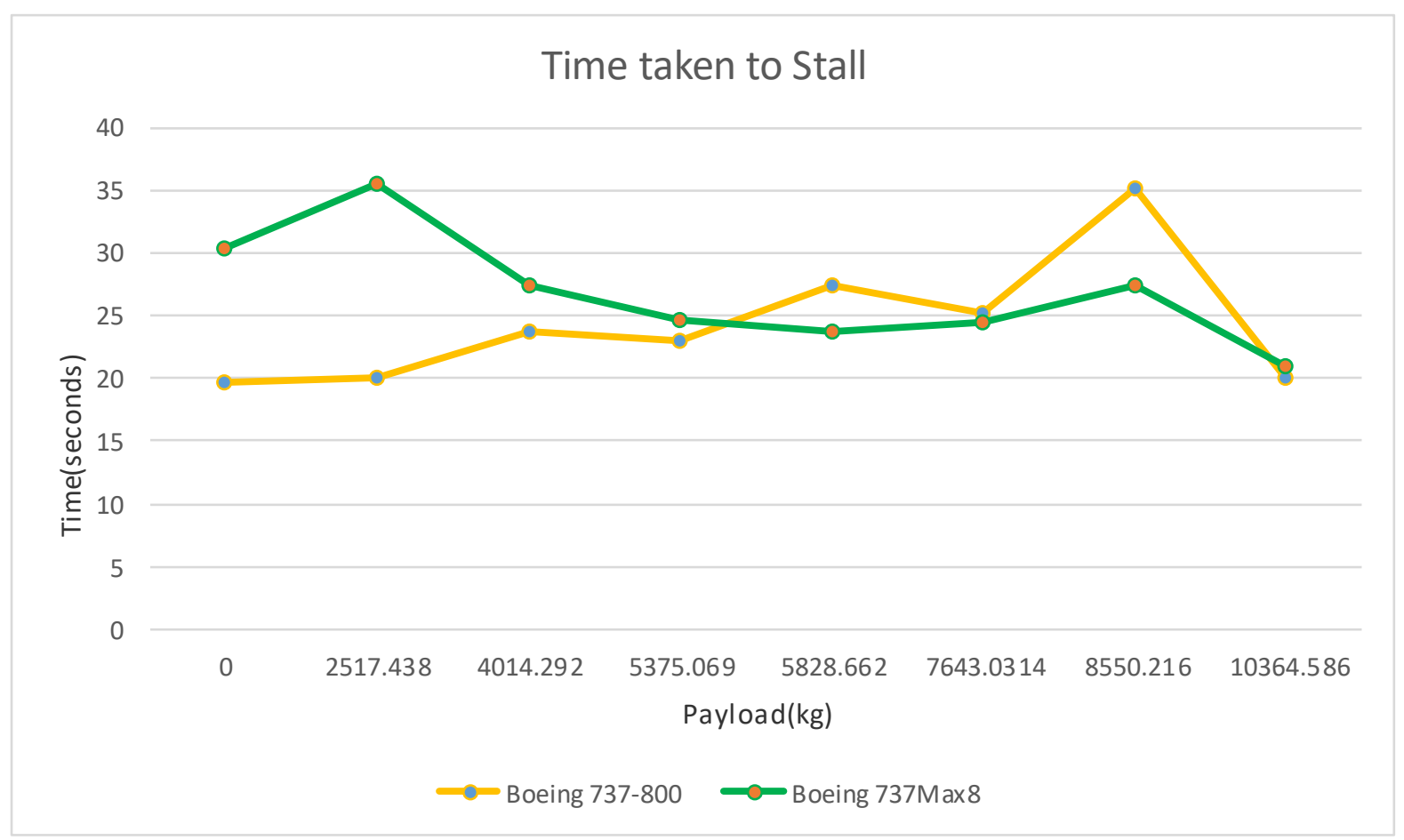

Conclusion 3.2.2

According to the above stall time charts, the Boeing 737-800 takes less time to stall in lower weight conditions than in heavy payloads. On the other hand Boeing 737, Max 8 is taking more time to stall at lower weights than in heavyweight conditions. This shows an inverse relationship between the two aircraft variants, concerning the stalling time. 
Graph 3.2.2 - Boeing 737-800 and Boeing 737 Max 8 stall angle comparison.

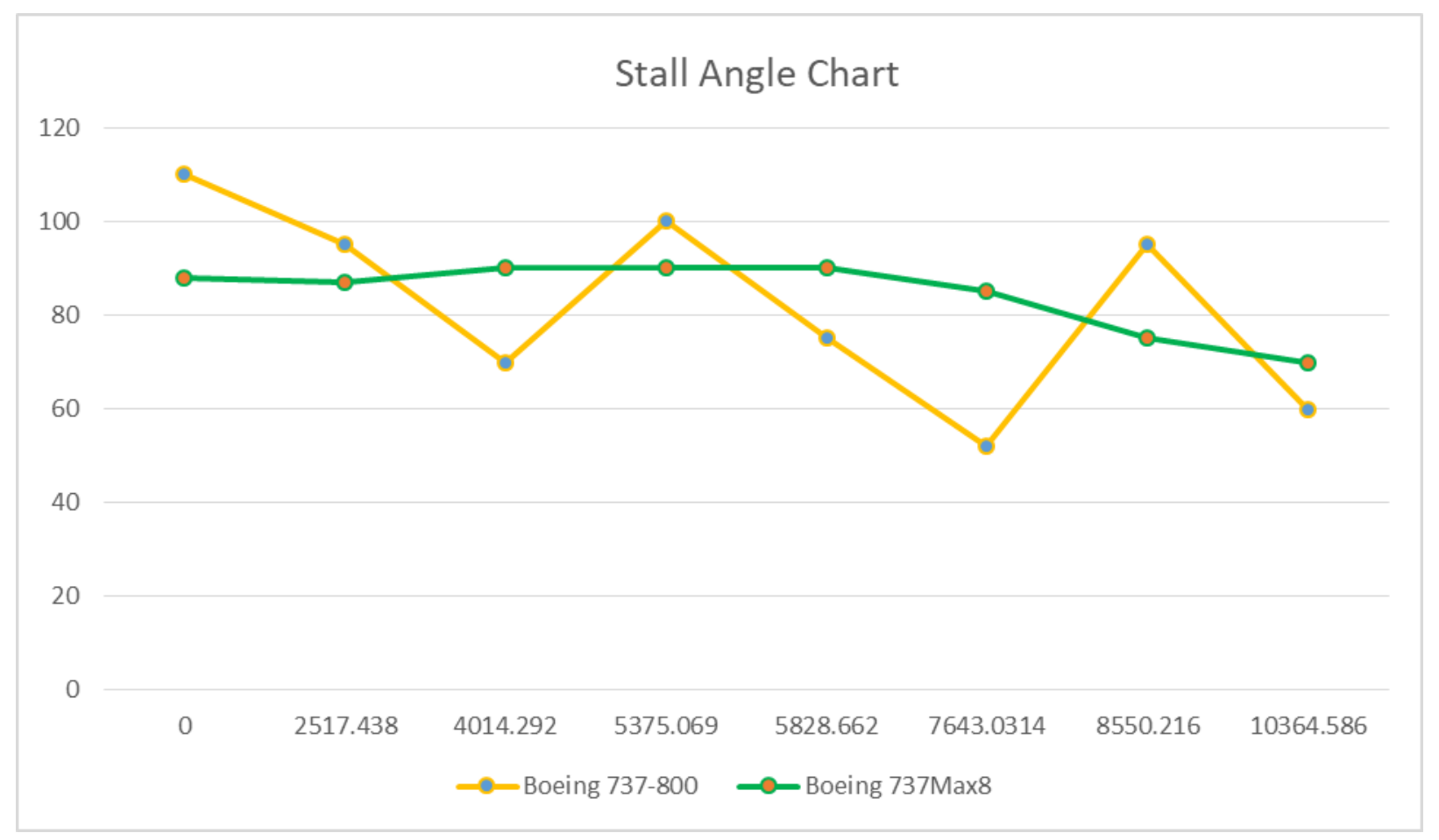

According to the results obtained in the simulation tests regarding the takeoff angle data and thrust levels of Boeing 737, Max 8 the JT610, and ET302 need to show the following angles and trim positions.

Note - The weights of each flight are taken as the average weight of the aircraft during the period of the crash and the flaps are considered to be a standard level of flaps levels of Max 8.

Thrust levels are relatively considered for the average value of the $\max 8$ thrust levels.

Table 3.2.3 - Simulated trim positions and pitch angles of JT610 and ET302

\begin{tabular}{|l|l|l|l|l|l|l|}
\hline 276. Flight & $\begin{array}{l}\text { 277. Weight } \\
\text { 278. (Payload + } \\
\text { Fuel load) }\end{array}$ & 279. Trim & 280. Flaps & $\begin{array}{l}\text { 281. V1 } \\
\text { 282. (knots) }\end{array}$ & $\begin{array}{l}\text { 283. Vr } \\
\text { 284. (knots) }\end{array}$ & $\begin{array}{l}\text { 285. Angle } \\
\text { 286. (Degrees) }\end{array}$ \\
\hline 287. JT610 & $\begin{array}{l}288.29,677.05 \\
\mathrm{~kg}\end{array}$ & $289 .+1.8$ & 290.15 & 291.119 & 292.147 & 293.8 \\
\hline 294. ET302 & $\begin{array}{l}295.25,709.47 \\
\mathrm{~kg}\end{array}$ & $296 .+1.8$ & 297.15 & 298.118 & 299.145 & 300.8 \\
\hline
\end{tabular}

According to the above analysis, both JT610 and ET302 are showing almost the same results, even though they are having a significant weight difference of nearly $3967.58 \mathrm{~kg}$. 
Graph 3.2.3 -Take off the angle analysis graph of JT610 and ET302.

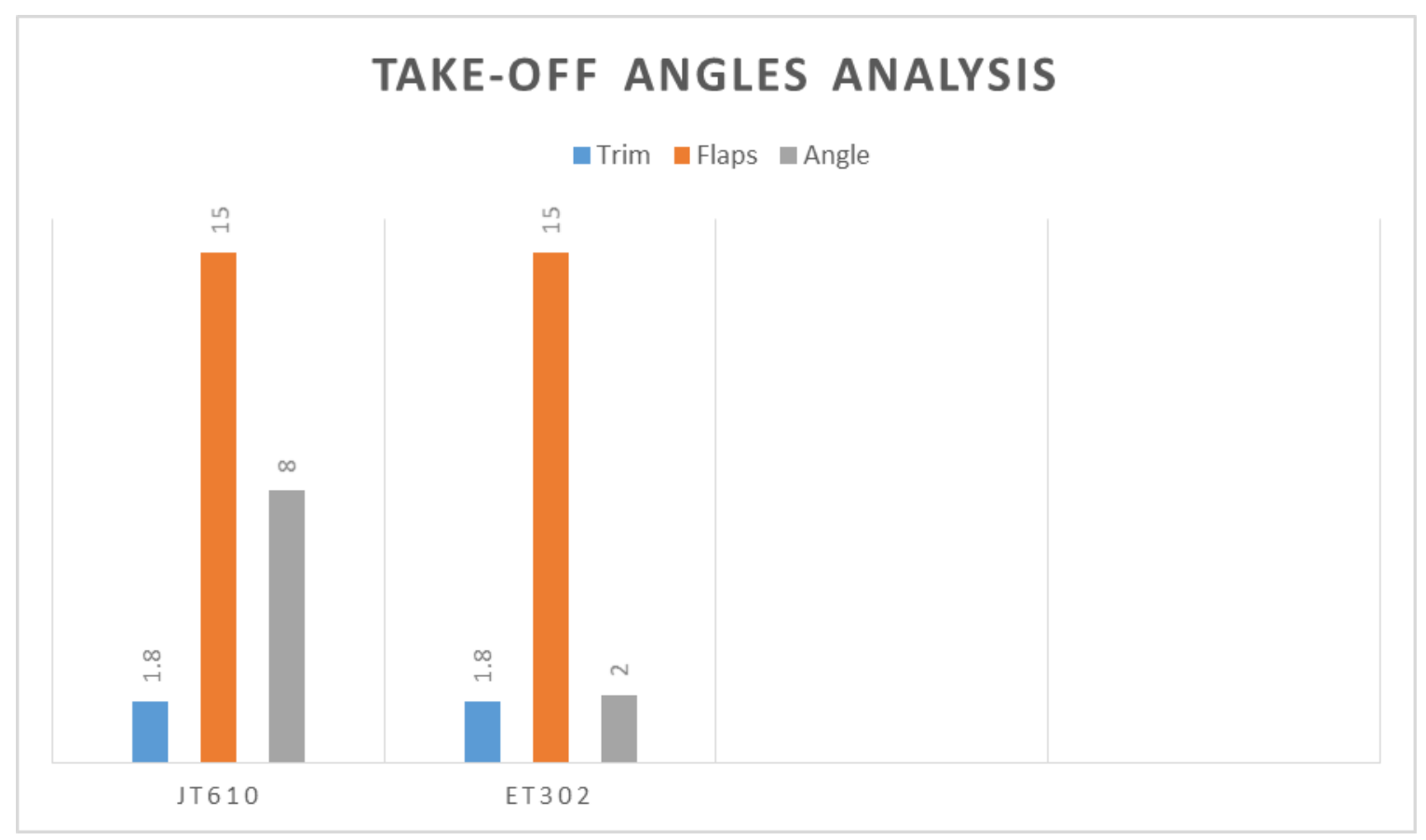

Graph 3.2.4 - take-off angle analysis graph of JT610 and ET302

\section{TAKE OFF SPEED DATA}

arim a Flaps av1 $\square$ V2 angle

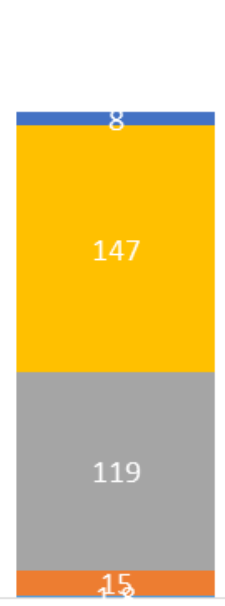

JT610

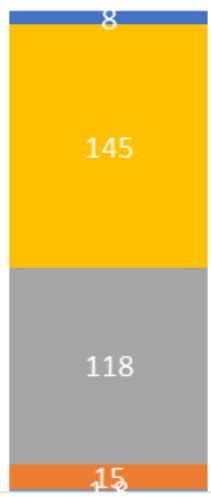

ET302 
Conclusion 3.2.3

The JT610 and ET302 showed almost the same takeoff angles when taking off. The takeoff speed of the two aircraft was different from each other only from 1-2 knots. All physical conditions affecting both flights had equal magnitudes up to the accuracy level of plus or minus 2 knots. This means that any effect that each aircraft experienced due to activation of MCAS or any issue in midflight, can be considered to be experienced by the other aircraft.

Now in project objective 3 there is clearly mentioned that the MCAS to be active the AOA should be high and the aircraft should be steeply turning. So according to the investigation results of FAA and NTSB to be MCAS to activate there should be a high AOA (Angle of Attack) in the flight pattern. To check this effect the stall margin analysis of the Max8 should be considered, that is done in the project objective 2 to find out the correct stall margins for the weights regarding each aircraft.

Table 3.2.4 - Stall simulation of JT610 and ET302

\begin{tabular}{|l|l|l|l|l|}
\hline 301. Flight & 302. Weight(kg) & $\begin{array}{l}\text { 303. Speed at stall } \\
\text { 304. (knots) }\end{array}$ & $\begin{array}{l}\text { 305. Time for stall } \\
\text { 306. (seconds) }\end{array}$ & $\begin{array}{l}\text { 307. The angle at } \\
\text { the stall. } \\
\text { 308. (degrees) }\end{array}$ \\
\hline 309. JT610 & $310.29,677.05 \mathrm{~kg}$ & 311.250 & 312.32 .03 & $\begin{array}{l}313.90 .35 \text { (vertical } \\
\text { turn over) }\end{array}$ \\
\hline 314. ET302 & $315.25,709.47 \mathrm{~kg}$ & 316.250 & 317.35 .72 & 318.87 \\
& & & & \\
\hline
\end{tabular}

According to the above-simulated results, both aircraft are reaching the stall margin with a time difference of 3.69 seconds and the important thing is that there is a stall angle difference of 3.37 degrees of stall angle difference.

But that 3.37 degrees difference is extremely deadly because the JT 610 is reaching and exceeding the vertical turn over the point of solid 90 degrees angle for the horizon. And this means that the aircraft is exceeding its final hopes of recovering from the stall and driving into the region of total control loss. 
Graph 3.2.5 - Stall margin analysis graph of JT610 and ET302

\section{STALL MARGIN ANALYSIS}

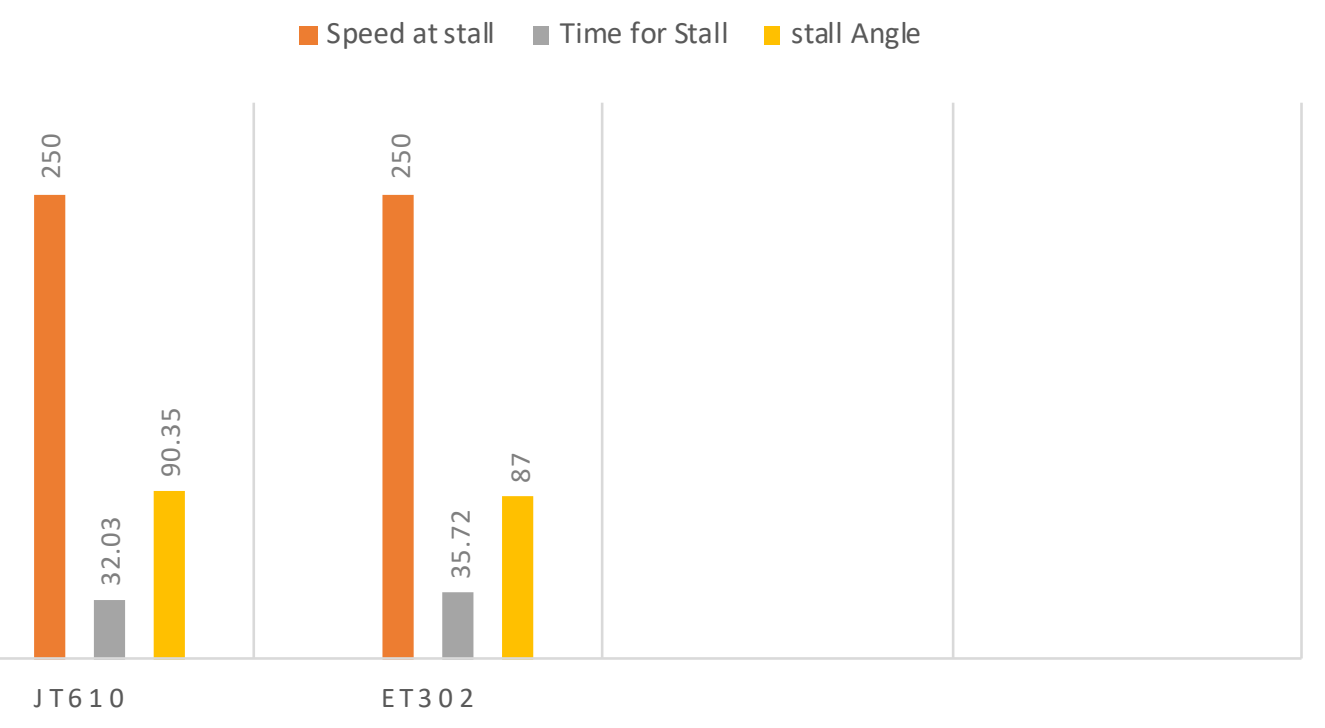

But if we assume that the JT610 and ET302 are Boeing 737-800 aircraft instead of MAX8 s, then the following table shows the simulated data of each aircraft regarding each weight.

Table 3.2.5- Stall simulation of JT610 and ET302 as Boeing 737-800

\begin{tabular}{|l|l|l|l|l|}
\hline 319. Flight & 320. Weight(kg) & $\begin{array}{l}\text { 321. Speed at stall } \\
\text { 322. (knots) }\end{array}$ & $\begin{array}{l}\text { 323. Time for stall } \\
\text { 324. (seconds) }\end{array}$ & $\begin{array}{l}\text { 325. The angle at } \\
\text { the stall. } \\
\text { 326. (degrees) }\end{array}$ \\
\hline 327. JT610 & $328.29,677.05 \mathrm{~kg}$ & 329.250 & 330.22 .09 & $\begin{array}{l}331.85(\text { vertical } \\
\text { turn over) }\end{array}$ \\
\hline 332. ET302 & $333.25,709.47 \mathrm{~kg}$ & 334.250 & 335.20 .25 & $\begin{array}{l}\text { 336. Vertical turn- } \\
\text { over reaches to } 84 \\
\text { degrees }\end{array}$ \\
\hline
\end{tabular}

Here an important point can be observed that when the load is increasing the time for the stall is also increasing. And that is something that can be observed with an inverse relationship to the data in the MAX 8. The analysis conducted with both conclusions considering the Jt610 and ET302 as MAX8 and 737-800 are plotted in a graph below. 
Graph 3.2.6 - Complete weight and stall analysis graph

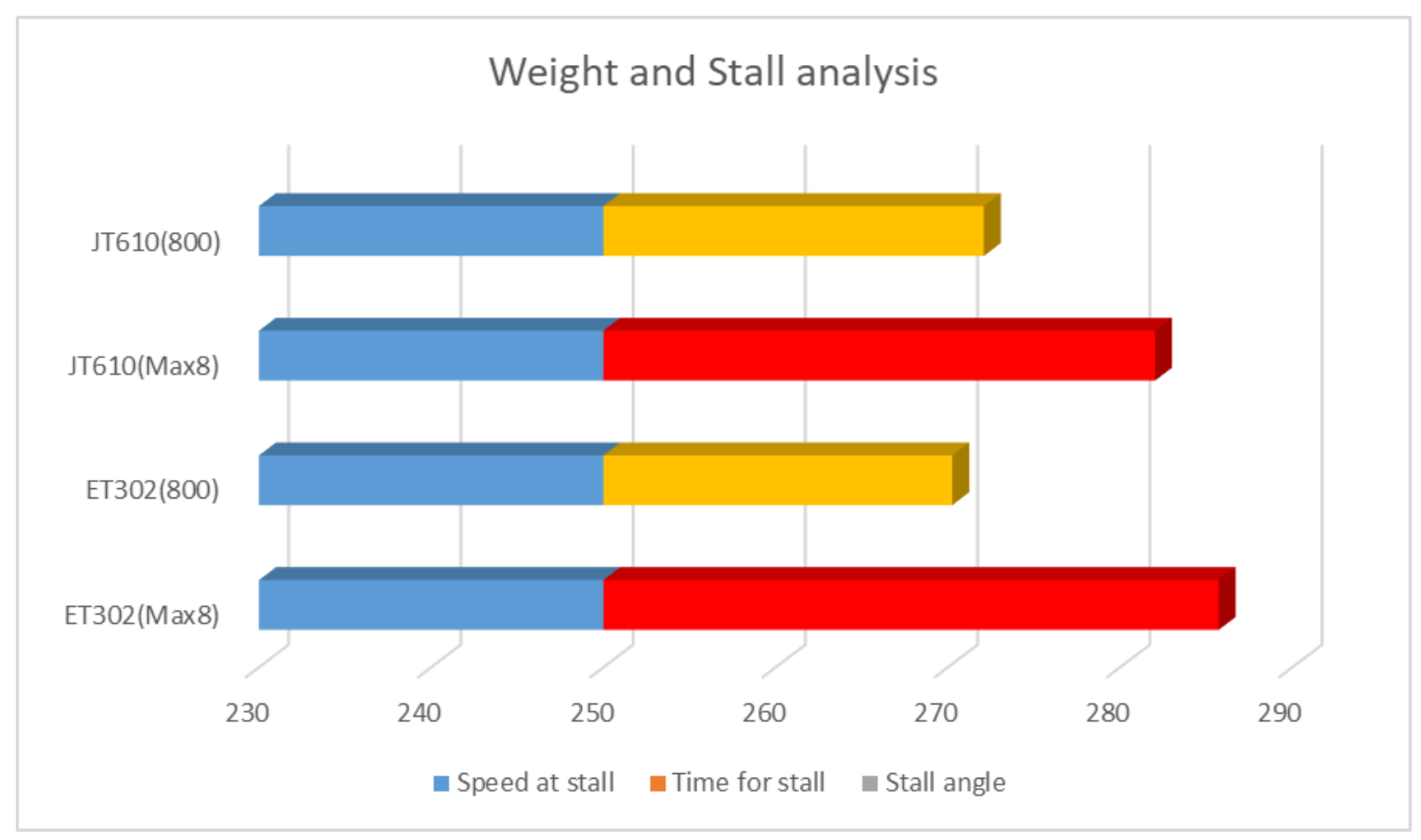

Conclusion 3.2.4

According to the above data that there is a piece of clear evidence proving that, the JT610 and ET302 pilots had more time to react and counteract to any situation or an issue that could have happened with leading to the point of a stall (coffin corner), than a Boeing 737-800 pilot.

And Boeing 737-800 has increased time to stall when the load is increasing. (Positive correlation).

The Boeing 737Max8 has reduced stall times when the load is increasing. (Negative Correlation).

\section{Conclusions}

The maximum pitch angle of the Boring 737-800 is reaching at the payload of $5375.069 \mathrm{~kg}$ sit is $52 \%$ of the total payload of the aircraft. The pitch angle at take-off in Boeing 737 max 8 appears to be a constant 8 degrees without exceeding the margin of 10 degrees. Boeing 737Max 8 is demanding double the amount of the elevator pitch trim, then the Boeing 737-800 to provide the same climbing angle under the equal weight conditions.

The V1 speed and the Vr speed are giving approximately close values in the Boeing 737-800 and they are reducing when the payload is reducing. But in Max 8 the V1 speed is the only one reducing with the weight and the $\mathrm{Vr}$ speed is changing slightly.

Boeing 737 - 800 is giving smooth take-off angles under all weight conditions, with less trimming. Boeing 737Max 8 gives the same take-off angles under the same equal weight conditions with double the trimming needed for Boeing 737-800.

Boeing $737-800$ is having close values in the V1 and Vr speeds, in various weights. And the difference between the two values is almost constant. Boeing 737Max 8 is having close values in V1 and Vr speeds 
under heavy payloads and the difference between them tends to tend to be increased when the payload is reducing.

According to the stall time charts, the Boeing 737-800 takes less time to stall in lower weight conditions than in heavy payloads. On the other hand Boeing 737, Max 8 is taking more time to stall at lower weights than in heavy-weight conditions. This shows an inverse relationship between the two aircraft variants, concerning the stalling time.

Boeing 737MAX 8 has a stable and constant value for the stall angle at given conditions while in Boeing 737 800 has a varying value to the stall angle.

According to the simulations and secondary data, The JT610 and ET302 showed almost the same takeoff angles when taking off. The takeoff speed of the two aircraft was different from each other only from 1-2 knots. All physical conditions affecting both flights had equal magnitudes up to the accuracy level of plus or minus 2 knots.

JT610 and ET302 pilots had more time to react and counteract to any situation or an issue that could have happened with leading to the point of a stall (coffin corner), than a Boeing 737-800 pilot.

And Boeing 737-800 has increased time to stall when the load is increasing. (Positive correlation).The Boeing 737Max8 has reduced stall times when the load is increasing. (Negative Correlation).

\section{Acknowledgements}

Special thanks to Eng. Thusitha Sameera Bandaranayake, BSc (Engineering), MBA, Engineer, Sri Lanka

Telecom PLC for providing the necessary supervision and the technical guidelines for the research.

Thanks to Mr. Jagath Jayawardana, BSc (Agriculture), MSc (Agri.Extension), Assistant General Manager (Marketing), Kurunegala Plantations LTD, Sri Lanka for giving advises on the formatting of the paper.

Thanks to Ms.Thushari Sudasinghe, Professional Author, for providing the proof reads for the content.

Thanks to Microsoft Cooperation and the Microsoft Flight Simulator X development staff and relevant authorities.

\section{References}

[1]. https://community.infiniteflight.com/t/using-the-737-800-900-flaps/191982, 2020

[2]. Boeing 737 MAX, 2020, https://www.boeing.com/commercial/737max/

[3]. Crash Report of Lion Air JT 610, 2019 - https://www.aviationtoday.com/2019/10/28/lion-air-737-maxfinal-accident-report-cites-aoa-sensor-mcas-as-contributing-factors/

[4]. "Boeing Assumed 737 Max Pilots Could Quickly Respond To Cockpit Warnings, NTSB Says", September 26, 2019, https://www.npr.org/2019/09/26/764664179/boeing-assumed-737-max-pilots-couldquickly-respond-to-cockpit-warnings-ntsb-say

[5]. "Boeing Next Generation", 2020, https://www.boeing.com/commercial/737ng/

[6]. December 19, 2019, Michael Lueck, Auckland University of Technology, "what's behind Boeing's production shutdown of MAX aircraft"

[7]. April 8, 2019, Carlos Varela, Rensselaer Polytechnic Institute, "Too many airplane systems rely on too 
few sensors"

[8]. March 26, 2019, Francesco Biondi, University of Windsor, "Human-centered design can help reduce accidents like the recent Ethiopian Airlines Boeing 737 crash"

[9]. March 20, 2019, Guy Gratton, Cranfield University, "Boeing 737 MAX: after two fatal crashes, an expert explains the issues'

[10.]. March 16, 2019, Timothy Takahashi, Arizona State University, "Automated control system caused Ethiopia crash, flight data suggests" 